\title{
FEM MODELLING OF A HELICAL WEDGE ROLLING PROCESS FOR AXISYMMETRIC PARTS
}

\author{
Zbigniew Pater ${ }^{1}$, Janusz Tomczak ${ }^{1}$ \\ 1 Mechanical Engineering Faculty, Lublin University of Technology, Nadbystrzycka 36, 20-618 Lublin, Poland, \\ e-mail: z.pater@pollub.pl, j.tomczak@pollub.pl
}

Received: 2017.11 .02

Accepted: 2018.02.01

Published: 2018.03.01

\begin{abstract}
The paper reports the results of a numerical analysis of helical-wedge rolling (HWR), a new metal forming method developed at the Lublin University of Technology. The numerical analysis was performed for three axisymmetric parts: a rotary cutter body, a stepped shaft and a ball pin. The numerical modeling was performed using the commercial simulation software Forge NxT 1.0. The paper examines changes in workpiece shape as well as variations in effective strains, temperatures, damage function, force parameters (on the rolls and guides), and torques acting on the rolls. It has been found that due to its advantages (low material losses and high efficiency), the new helical-wedge rolling process can be used as an alternative to currently employed methods for producing axisymmetric products.
\end{abstract}

Keywords: helical-wedge rolling, tools, force parameters, FEM

\section{INTRODUCTION}

Metal forming methods are widely used to produce axisymmetric parts in the mining, automotive, aircraft and engineering industries as well as a number of other industrial branches. Metal forming methods for producing such parts include die forging, rotary forging, machine forging, extrusion forging, and forge rolling [1]. Despite many techniques for forming axisymmetric parts, new methods are developed with an aim to reduce material and energy consumption in the production process. One of the new methods that seems to ensure that is helical-wedge rolling (HWR), a process that is a development of the helical rolling technique (HR).

Helical rolling is widely used to produce balls for grinding media. The technique was invented in 1928 by an American named Hodge and consists in using a machine with skew-positioned rolls and guides [2]. Before World War 2 (1936), a method was developed in the USA for forming bearing rings from a tube mounted on a mandrel, using two or three helical rolls [3].
Despite the fact that the fundamentals of helical rolling were mainly established in the United States, the method was practically applied on a mass scale in the former USSR. In about 1950 a Soviet research team led by Celikov constructed the first industrial skew rolling mill. Based on the design of the machine, they devised a rolling method for producing balls with diameters ranging from 25 to $45 \mathrm{~mm}$. In 1956 OAO "EZTM," a company based in Elektrostal (now: Russia), launched production of commercial roll mills for forming balls. The range of products manufactured using these machines was next extended to include ball bearing rollers and ribbed pipes [4].

In the early 1970s two Toyota Company employees, Awano and Danno, were granted a patent [5] for a new helical rolling method for forming mainly axisymmetric preforms. The method consisted in the use of rolls with helical wedges for reducing billet diameter. Thereby designed helical rolling process was inspired by technological solutions adopted in a popular forming technique of cross wedge rolling (CWR) [6]. A novelty of the proposed helical rolling method was that the 
wedges were located over some area of the circumference of the rolls. The authors of the patent also allowed for winding the wedges on the rolls with a hypoid profile.

The assumptions of the HWR process proposed in this paper were established at the Lublin University of Technology as a part of research and development works on designing new practical methods for producing balls [7]. The main assumption of the technique is that balls are formed by wedges that are wound helically (in a singleor multi-coil manner) on the roll face. The numerical and experimental results have confirmed the correctness of the solution [8-10].

HWR seems be an effective method for producing parts that have a more complex shape than balls. To verify this hypothesis, extensive numerical analyses were performed at the Lublin University of Technology, focusing on the possibility of producing axisymmetric parts such as rotary cutter bodies, stepped shafts and ball pins by the proposed method. A selection of the results is reported in this paper.

The numerical analysis was performed using the computer simulation software Forge NxT 1.0 based on the finite element method (FEM). The software enables not only an analysis of workpiece shape changes, but prediction of the material separation moment, which is vital in HWR. Last but not least, this software was used previously by the authors for modeling cross and skew rolling processes [11-15].

\section{DESIGN OF THE HELICAL WEDGE ROLLING PROCESS}

Fig. 1 shows the schematic design of a HWR process for producing balls. In this process, the forming wedges are wound helically on the roll face. The ball is formed by two identical rolls that are positioned askew to the axis of the billet (cylindrical bar). To maintain the billet's position between the rolls, additional guides are used. Rotated in the same direction, the wedges on the rolls cut into the workpiece, thereby putting it into rotational and translational motion (relative to the axis of the billet). The workpiece is given the desired shape by the helically moving wedges. In the final stage of the process, the formed ball is cut off from the billet (cylindrical rod) by the cutters located right behind the wedges.

The helical tools (wedges) are described by two angles: the forming angle $\alpha$ and the spreading angle $\beta$ (Fig. 1). They are wound on the roll face and have a variable pitch, its value ensuring that the volume of material in the roll pass is equal to the volume of the workpiece in every moment of the rolling process. The design of the tools for HWR must take account of workpiece elongation in every stage of the rolling process. The values of the angles $\alpha$ and $\beta$ can be applied based on a formula established for the CWR process [6], according to which:

$$
0.04 \leq \tan \alpha \tan \beta \leq 0.08
$$

\section{ROTARY CUTTER BODY}

The proposed HWR method is suitable for producing parts in large batches. Therefore, it seems justified to employ this technique in production of rotary cutter bodies (Fig. 2). Nowadays such parts are manufactured by die forging (end waste in the form of flash) and CWR (side waste due to removal of funnel-like shape defects).

The implementation of the HWR method to produce rotary cutter bodies requires the use of tools (rolls) with the shape shown in Fig. 3. These tools have a nominal diameter of $450 \mathrm{~mm}$ (the diameter is equal to the spacing between the axis of the rolls) and a length of $470 \mathrm{~mm}$. The wedge is wound helically on the roll that is

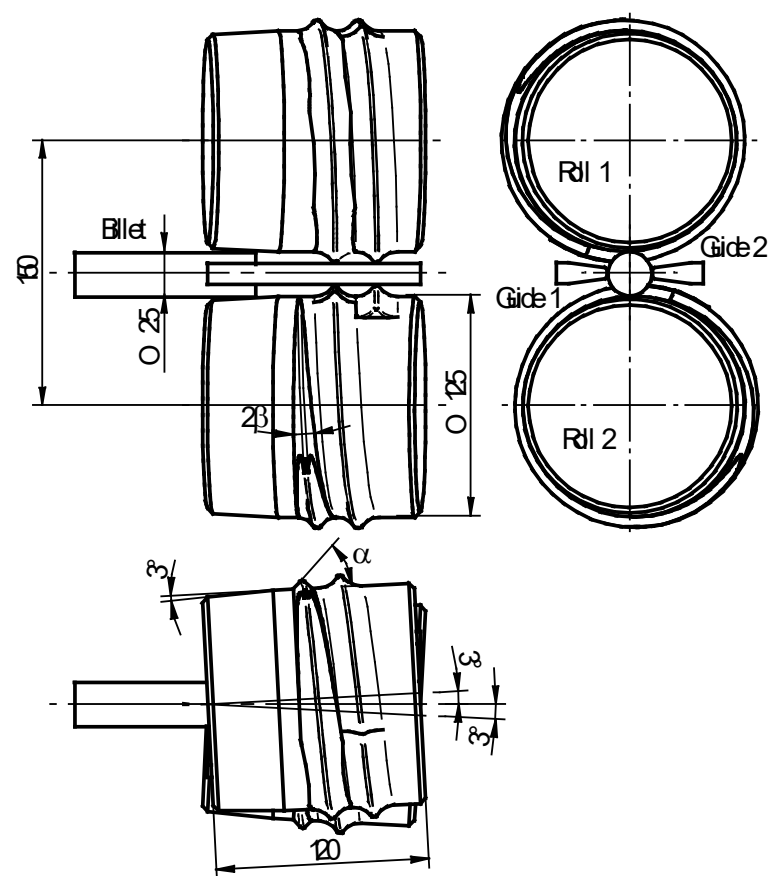

Fig. 1. Schematic design of a HWR process for producing $25 \mathrm{~mm}$ diameter balls 


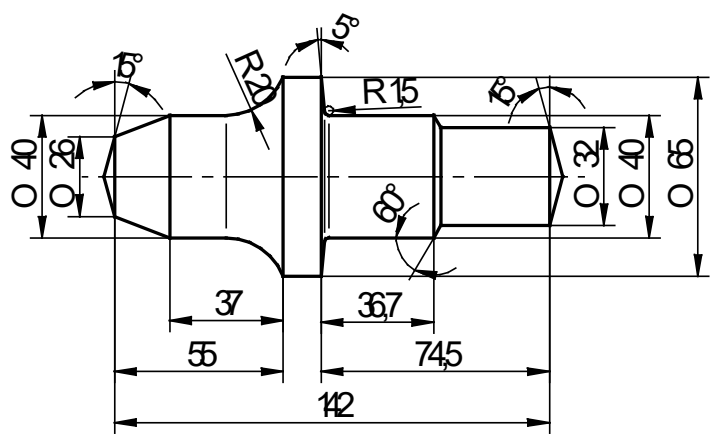

Fig. 2. Schematic design of a rotary cutter body
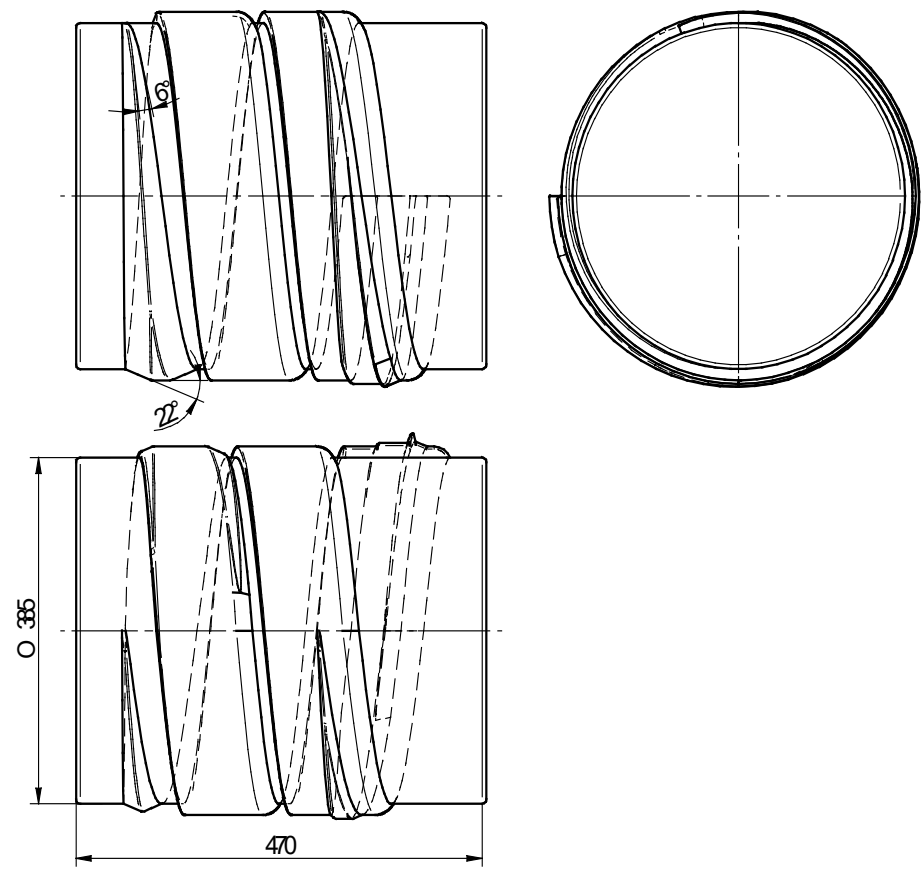

Fig. 3. Helical roll for forming a rotary cutter body

described by the spreading angle $\beta=6^{\circ}$ and the forming angle $\alpha=22^{\circ}$.

As already mentioned, the proposed HWR method for producing a rotary cutter body was verified by numerical modeling. Fig. 4 shows the geometrical model of the HWR process for a rotary cutter body. The model consists of two identical helical rolls, two linear guides, a tubular guide, and a cylindrical billet with a diameter of $65 \mathrm{~mm}$ and a length of $350 \mathrm{~mm}$. The tools are modelled as perfectly rigid bodies while the billet $(41 \mathrm{Cr} 4$ steel $)$ is assigned the properties of an elastic-plastic material obtained from the material database of the software used. The parameters applied in the modelling of the HWR process for producing a rotary cutter body were as follows: the feed angle was set to $3.5^{\circ}$; the rotational speed of the rolls was set to 15 revolutions per minute; the friction factor was set at 0.9 for the rolls and 0.3 for the guides; the temperature of the tools was set to $250^{\circ} \mathrm{C}$; the billet was preheated to the temperature of $1150^{\circ} \mathrm{C}$; the workpiece-tools heat transfer coefficient was equal to $10 \mathrm{~kW} / \mathrm{m}^{2} \mathrm{~K}$.

The workpiece was modelled using 4-node tetrahedral finite elements, with the mesh refined over the area of tool impact. Owing to changes in the workpiece shape during rolling, the number of these elements had to be increased. This combined with short time step led to a longer process time - in the analyzed case, the CPU time was nearly 80000 seconds (the modeling was performed using a 32-core PC with 64 GB RAM) - Fig. 5.

The numerical results demonstrate that HWR is a viable method for producing rotary cutter bodies. The design of the rolling process is illustrated in Fig. 6. The part is formed in three revolutions 


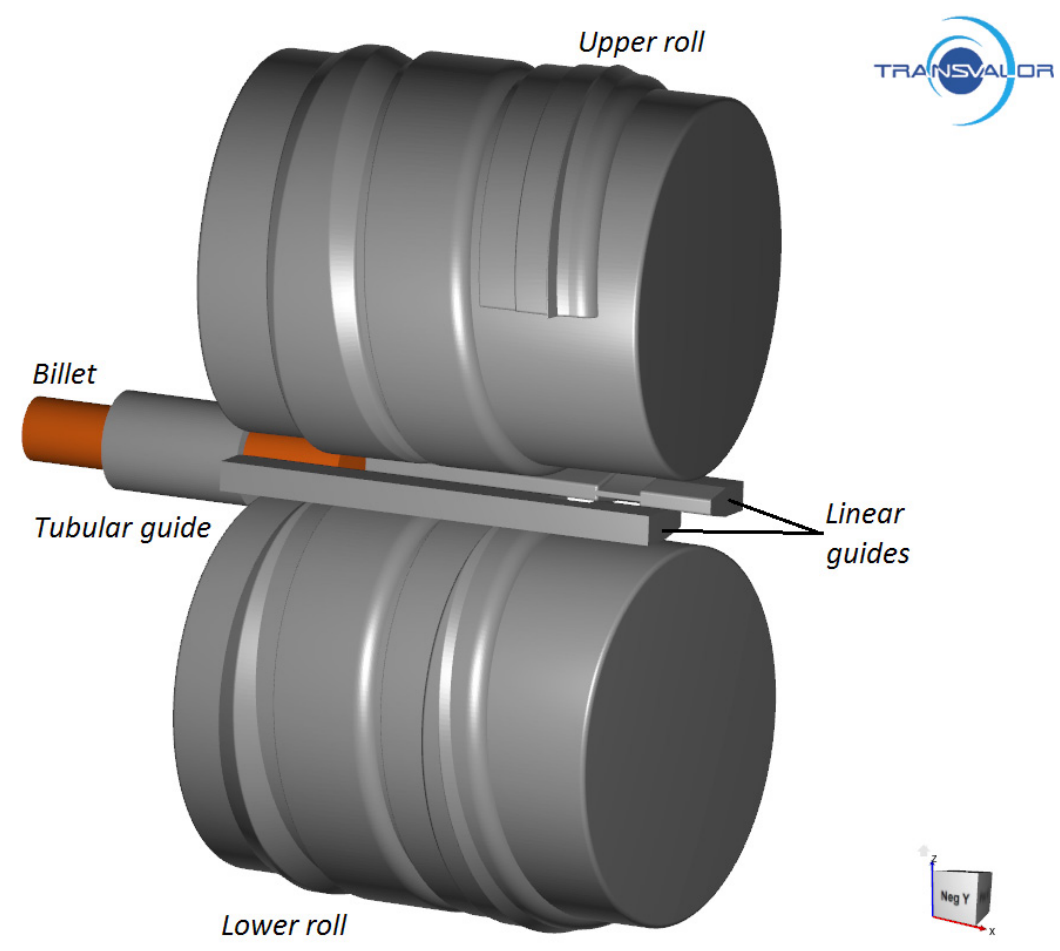

Fig. 4. Geometrical model of HWR for a rotary cutter body designed by Forge NxT 1.1

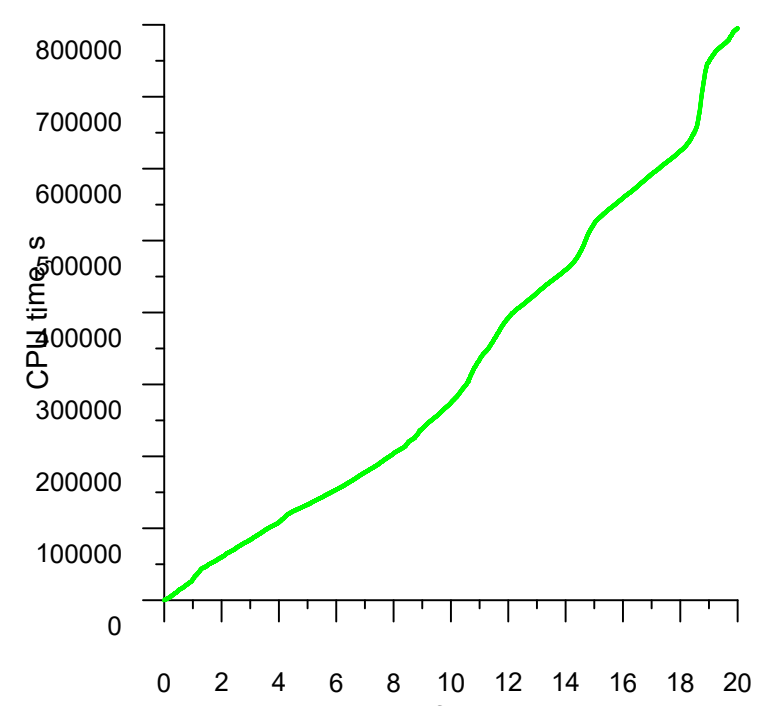

Fig. 5. Diagram illustrating the CPU time in HWR for a rotary cutter body vs. time of rolling in numerical analysis by a 32 -core PC

of the rolls. During the first revolution, necking is formed between the adjacent collars; the necking has a diameter of $40 \mathrm{~mm}$, which is equal to the diameter of the bigger step of the shank. Then, in the second revolution of the rolls, the necking undergoes sizing but its shape remains unchanged. Finally, during the third revolution of the rolls, a smaller step of the shank and a conical area of the part's head are formed simultaneously. Finally, the rotary cutter body formed during the previous revolutions of the rolls is cut off with the cutter.

The part is formed after 12 seconds, which equals to three complete revolutions of the rolls. This relatively long forming time does not, however, lead to a significant drop in the temperature of the workpiece. As can be seen in Fig. 7, the temperature of the part produced by HWR remains in the hot forming range. It is the lowest at the surface due to contact of the workpiece with the much colder tools and the resulting heat transfer. In contrast, the temperature in the axial area of the workpiece is by several dozen degrees higher, exceeding $1050{ }^{\circ} \mathrm{C}$.

Figure 7 also illustrates the variations in effective strains in the axial section of the produced rotary cutter body. It can be observed that the strains increase with increasing cross-sectional reduction: they are the highest in the area where separation of the parts takes place. It is worth drawing attention to the fact that the high effective strains cannot be explained by the observed change in the workpiece shape. These strains predominantly result from rapid metal flow in a circumferential (tangential) direction, which causes so-called redundant strains.

Figure 7 shows the damage function determined in compliance with the Cockroft-Latham 


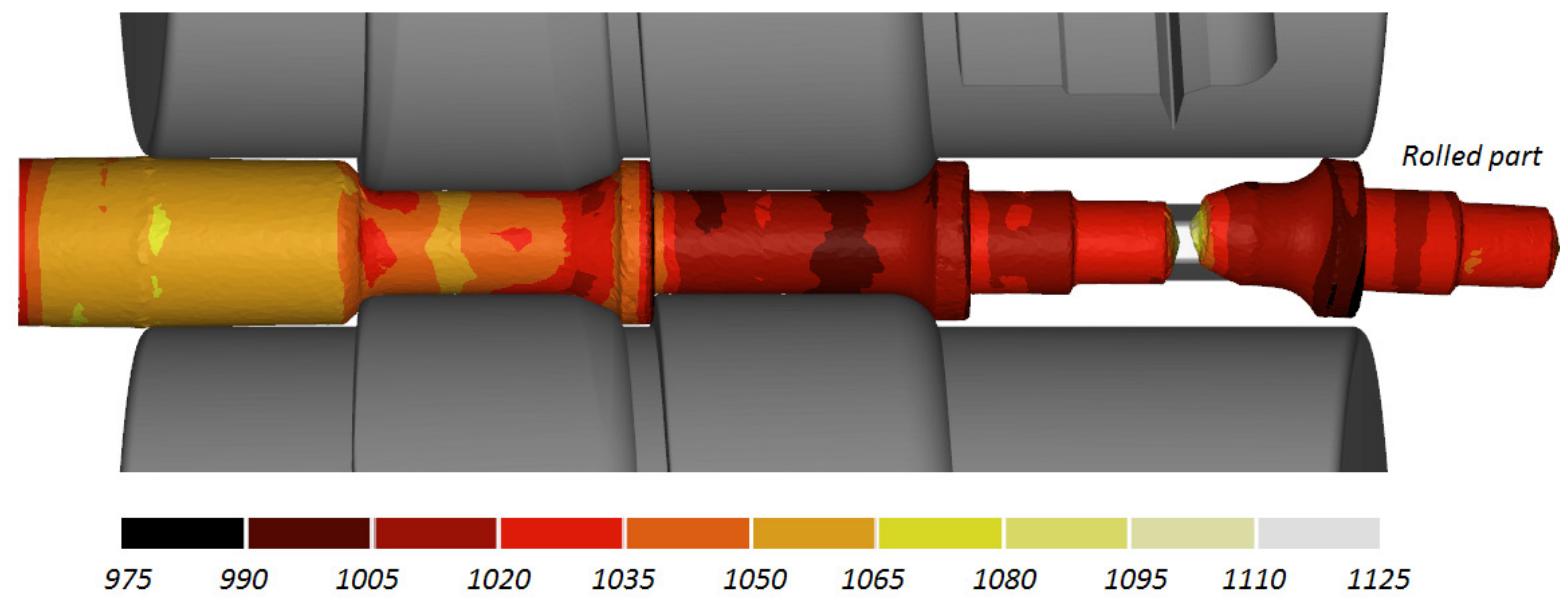

Fig. 6. Shape of the workpiece in an advanced stage of HWR, i.e. when $t=15.4 \mathrm{~s}$, and the distribution of temperature in the workpiece $\left(\right.$ in $\left.^{\circ} \mathrm{C}\right)$

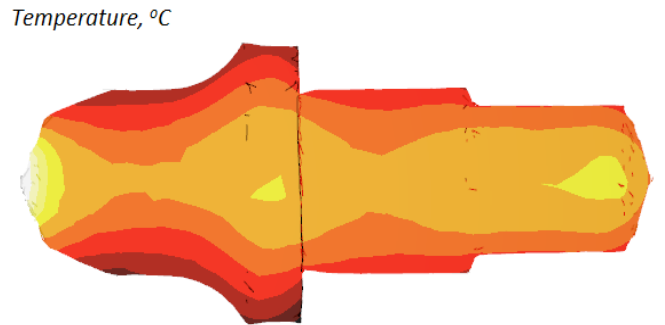

$975990 \quad 100510201035 \quad 1050 \quad 1065 \quad 1080 \quad 1095 \quad 1110 \quad 1125$

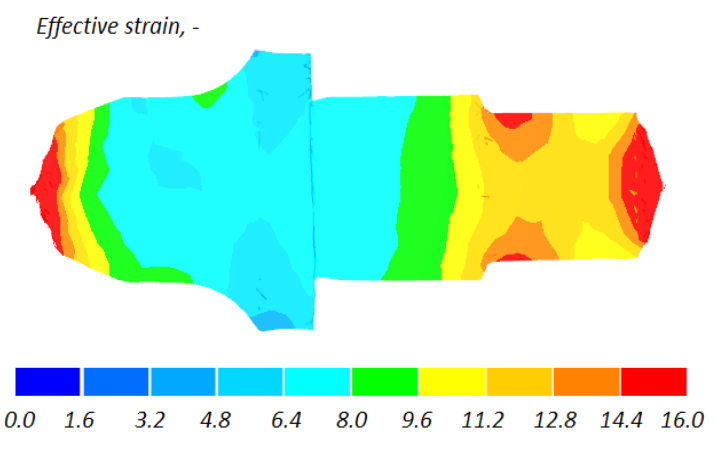

Damage function, -

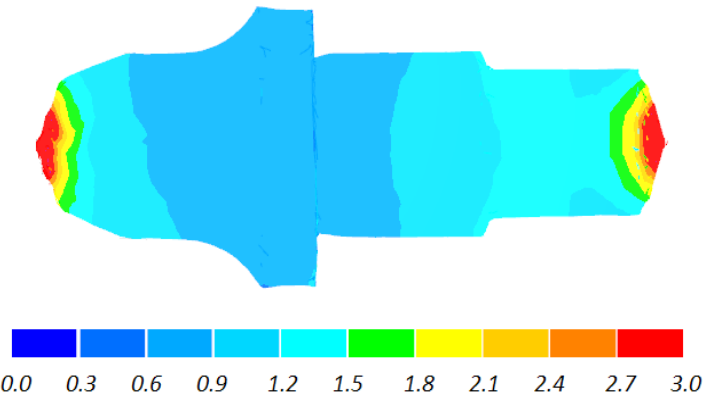

Fig. 7. Starting from top: the distribution of temperature (in ${ }^{\circ} \mathrm{C}$ ), effective strains and damage function (according to the Cockroft-Latham criterion), determined for the axial section of a rotary cutter body produced by HWR criterion. It can be observed that the function attains the highest values on the workpiece ends, where finished parts are cut off by the cutters. However, the damage function does not increase in the axial area of the workpiece. It can therefore be presumed that the product will be free from axial cracking (Mannesmann effect) that often occurs in cross and skew rolling processes.

Due to the use of FEM it was possible to examine variations in force parameters during the HWR process for rotary cutter bodies. The data given in Fig. 8 demonstrates that the radial load in the analyzed process varies in a cyclical fashion. In the steady stage of the rolling process (after $12 \mathrm{~s}$ ), the mean radial load is approx. $700 \mathrm{kN}$. The cyclical variations in this load result from the wedge's periodic cutting into the workpiece.

Fig. 9 illustrates the variations in loads acting on the linear guides. The highest load occurs in a tangential direction. This is due to the impact of the guides that prevent the workpiece from being pushed out from the workspace of the rolls. Nonetheless, this load is approx. 20 times lower than the load acting on the rolls. The axial and radial loads acting on the guides have insignificant values.

The distribution of the torque on the roll (Fig. 10) is identical to that of the radial load. In the steady stage of the process the mean torque is $9.3 \mathrm{kNm}$ (its highest value is $14.1 \mathrm{kNm}$ ). The torque results demonstrate that the HWR process should be performed using rolling mills equipped with a flywheel. 


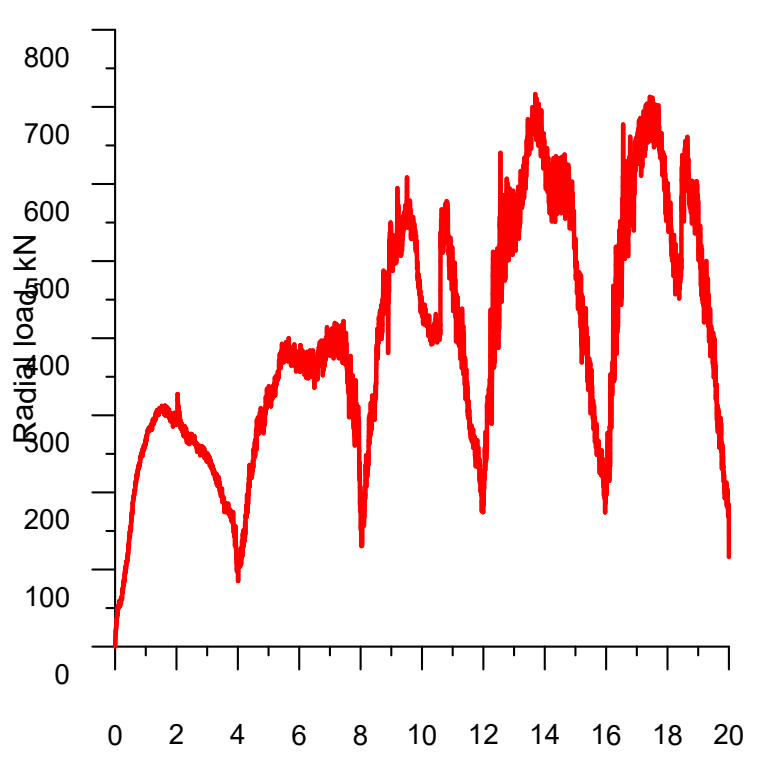

Fig. 8. Radial load on one roll in HWR for a rotary cutter body

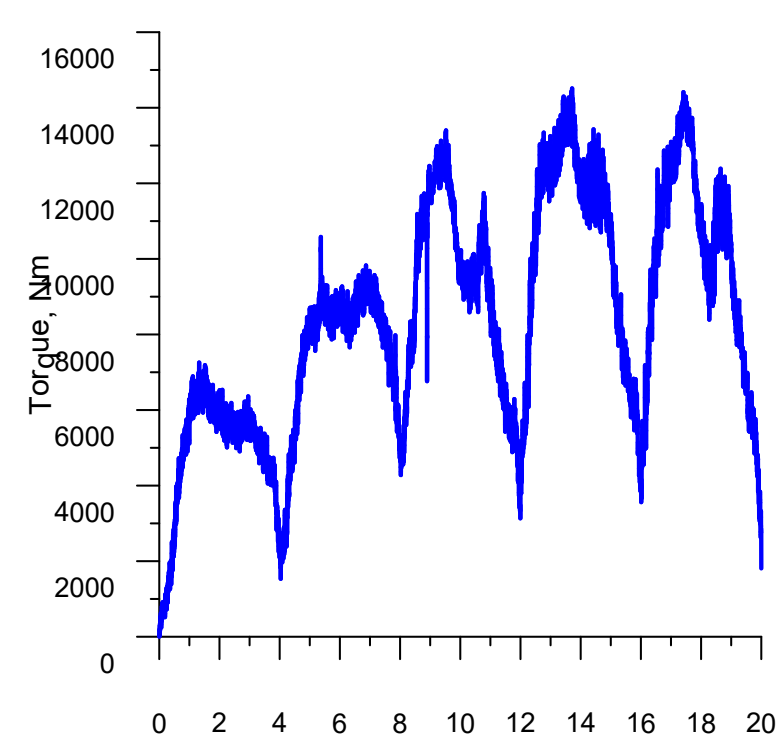

Fig. 10. Torque on the roll in HWR for a rotary cutter body

\section{STEPPED SHAFT}

The HWR method can also be used to produce stepped axes and shafts that are nowadays predominantly manufactured by die forging and CWR. However, the usefulness of the latter two methods is limited when it comes to shorter parts, as the use of these techniques leads to higher material losses in the form of flash (die forging) and end waste (CWR). One of these shorter parts is a stepped shaft shown in Fig. 11. When produced by CWR, this shaft must be formed in two stages (due to triple reduction of end steps). In the

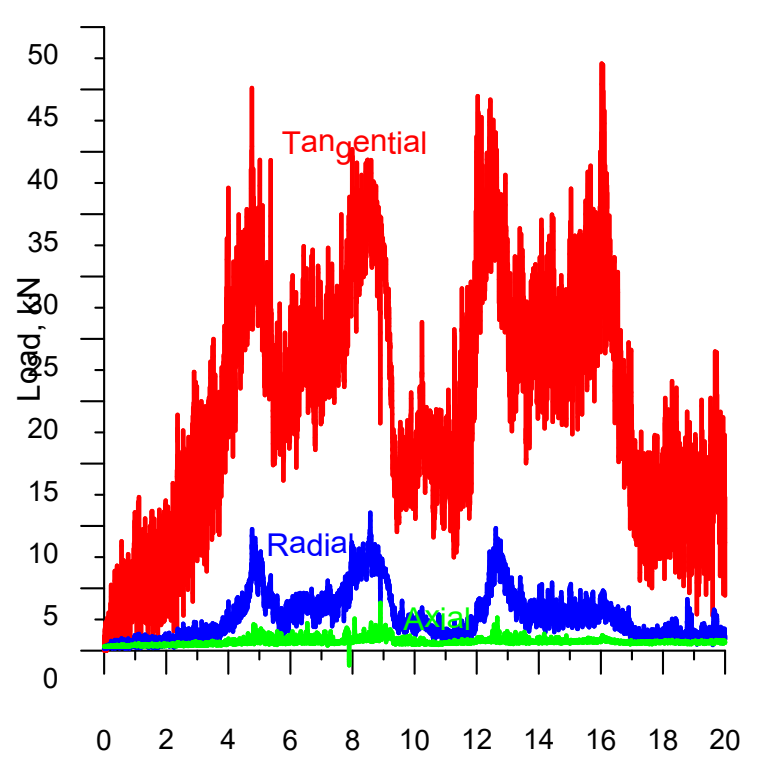

Fig. 9. Loads acting on the guide in tangential (y acc. to Fig. 4), radial (z) and axial (x) directions in HWR for a rotary cutter body

first pass, a shaft step with a $35 \mathrm{~mm}$ diameter is formed. Then it is formed into an end step with a diameter of $20 \mathrm{~mm}$. Given the kinematics of metal flow in the CWR process, funnel-like shape defects tend to form on the workpiece front-end [6, 16]. To remove them, the workpiece length must be increased. In the case of the analyzed shaft, the machining allowance to remove the funnel-like defects must be very large. According to the results reported in [17], material losses in the CWR process for producing this part amount to $39.4 \%$.

The above-mentioned shape defect does not occur when the HWR process is performed using the roll shown in Fig. 12. As in CWR, the use of this tool ensures that rolling can be performed in two stages. During the first half-revolution of the roll, wedge 1 cuts into the billet and forms a step with a diameter of $35 \mathrm{~mm}$. In the next revolution of the roll, the formed step undergoes sizing. The sizing zone of the tool is made longer in order to prevent necking of the step during the following half-revolution of wedge 2 that forms a $20 \mathrm{~mm}$ diameter step (it is blocked axially by other steps of the shaft, their highest diameter being $60 \mathrm{~mm}$ ). In the final stage of the HWR process, the formed shaft is cut off by the cutters. The wedges have a variable helix pitch to ensure that in every stage of the process the volume of material constrained in the roll pass is equal to that of the shaft.

The proposed HWR process for producing a stepped shaft was verified by numerical modelling. The billet used in the modelling had a diameter of $60 \mathrm{~mm}$ and a length of $180 \mathrm{~mm}$. It was 


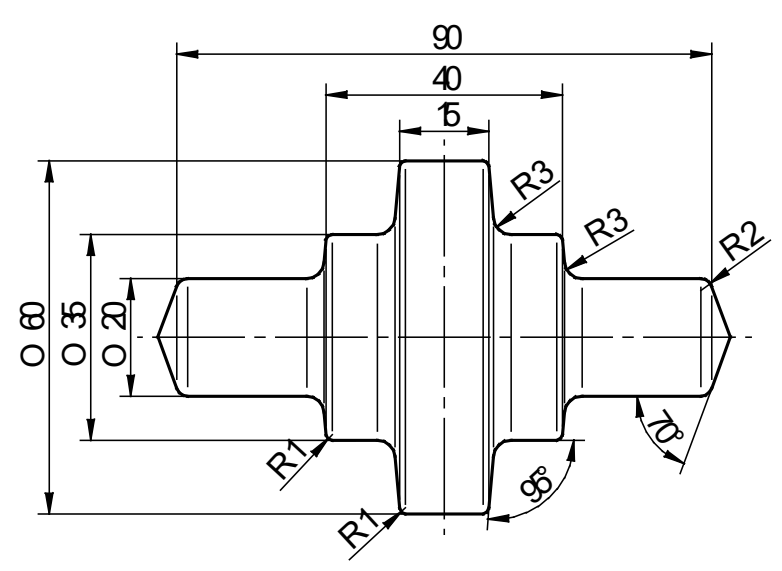

Fig. 11. Schematic design of a stepped shaft

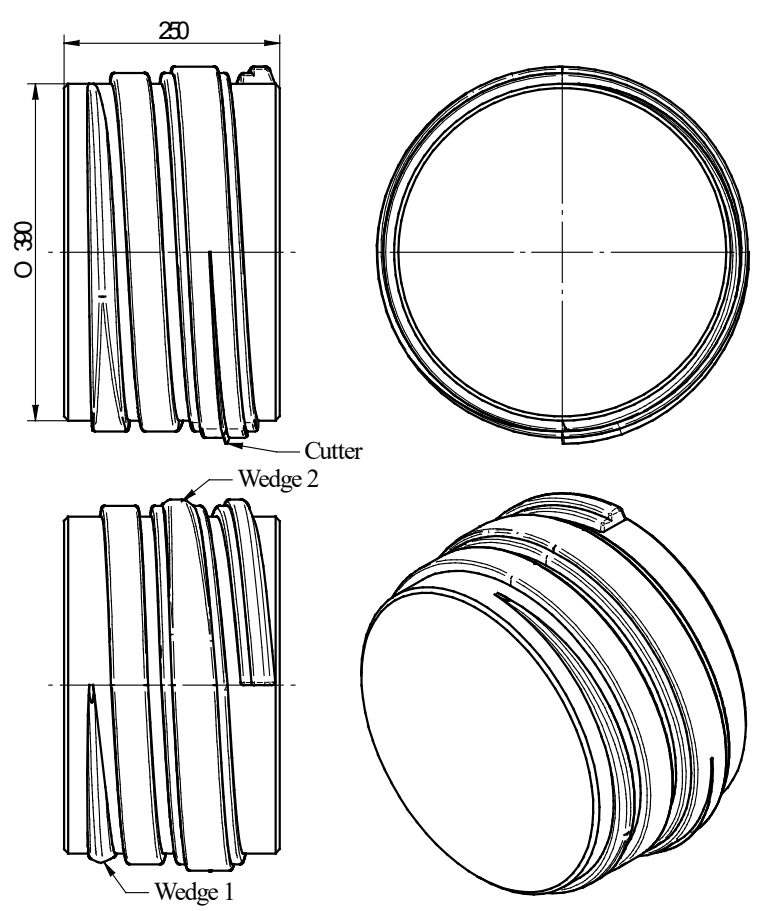

Fig. 12. HWR tool for forming a stepped shaft

deformed by two identical helical rolls that were set askew at an angle of $3.5^{\circ}$ relative to the axis of the workpiece and rotated at the same speed set to 15 revolutions per minute. The billet was assigned the properties of $\mathrm{C} 45$ steel (its model was obtained from the material database of the software) and preheated to the temperature of $1150^{\circ} \mathrm{C}$, and the temperature of the tools is maintained constant during the forming process at $150^{\circ} \mathrm{C}$. Other parameters were identical to those applied in the modelling of a HWR process for producing a rotary cutter body.

The numerical results demonstrate that the proposed forming method should enable producing stepped shafts with the desired shape (Fig. 13). A characteristic of HWR is that the process is continuous. The amount of technological waste is limited - merely two not fully formed parts made from the ends of the billet. As a result, depending on the billet length, the yield in HWR is significantly higher - it amounts to $96.5 \%$ for the billet with a diameter of $60 \mathrm{~mm}$ and a length of 1000 $\mathrm{mm}$ and to $98 \%$ for the billet that is two times longer. What is more, it is worth drawing attention to high efficiency of the rolling process - 15 parts per minute at the applied rotational tool speed.

Figure 14 shows the distributions of effective strains, damage function and temperature in the produced part. Obviously, the highest strains occur in the area of the biggest cross sectional reduction. Nevertheless, the workpiece undergoes deformation also in the biggest shaft steps where the cross sectional reduction is equal to 0 , which results from the circumferential metal flow caused by the friction forces. Interestingly, too, despite the symmetric shape of necking, the strains are not uniform on both sides of the collar. The differences can be explained by additional axial impact of the wedge on the workpiece, which leads to axial shift of the workpiece during rolling.

Based on the data given in Fig. 14, it can be claimed that the HWR process for a stepped shaft will be free from axial cracking. Analyzing the distribution of the Cockroft-Latham integral one can observe that the integral attains the highest values only in the area of impact of the cutters, hence in the area where material separation should take place.

Figure 14 also provides information about the variations in workpiece temperature during the rolling process. The shaft is formed during three successive revolutions of the rolls, which takes 12 seconds. Despite such a long forming time, the temperature drops in the forming zone are not significant: in the case of the smallest diameter shaft steps, the temperature only decreases by $100 \div 150^{\circ} \mathrm{C}$. At the same time, the temperature in the biggest step (collar) - one that does not undergo diameter reduction - decreases (at the surface) even by over $250^{\circ} \mathrm{C}$. This means that the HWR process generates large amounts of heat that compensates for heat carried away to the tools, which enables continuing the rolling process without a significant increase in the forming forces.

The numerical results of the HWR process for a rotary cutter body reveal that the helical tools are subjected to the highest load during this process. Figure 15 shows that the highest load acting on the roll in the HWR process for a stepped shaft is $143 \mathrm{kN}$. This value is not very high, especially 


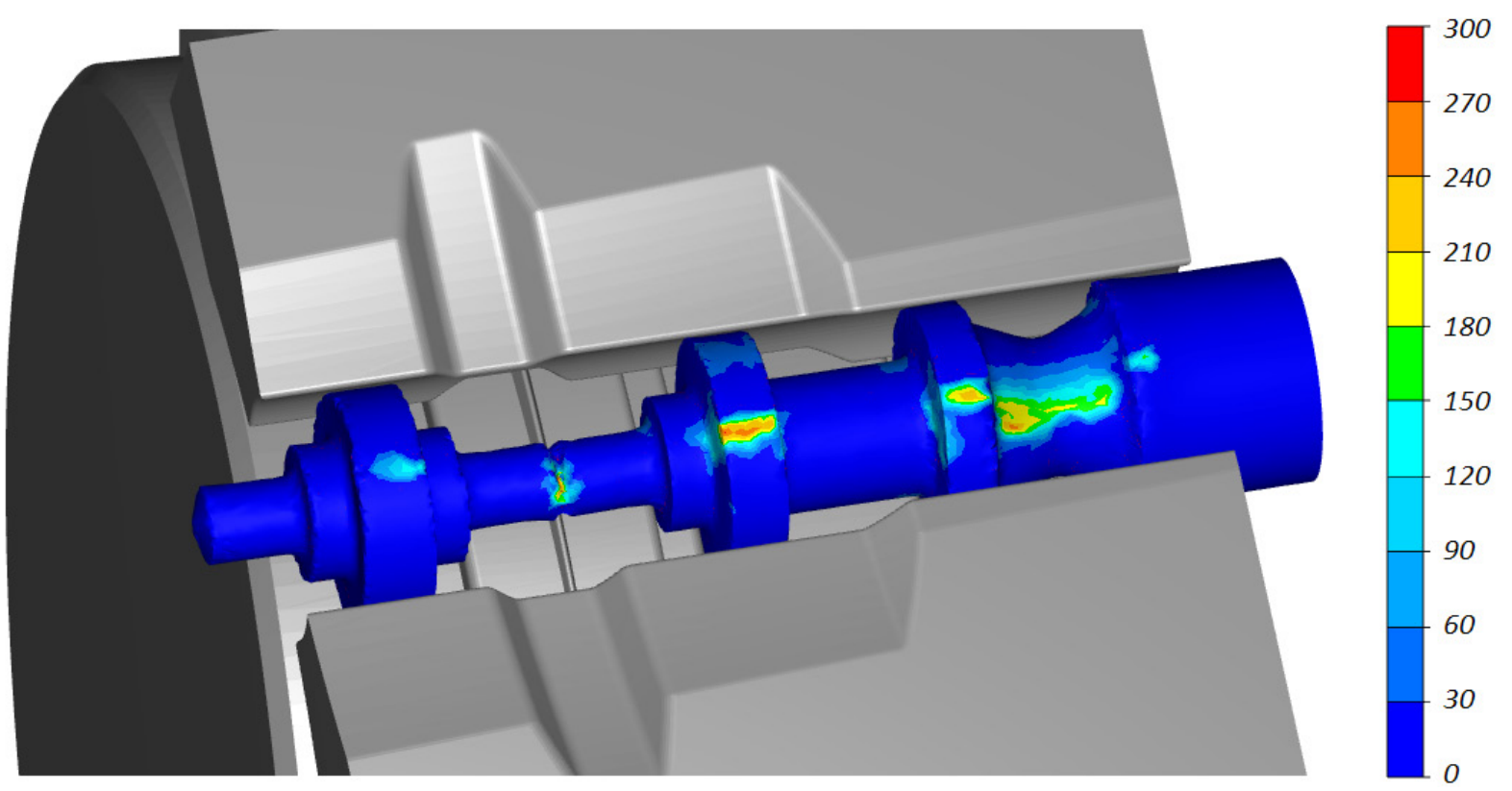

Fig. 13. View of the workpiece in an advanced stage of the rolling process $(t=13.2 \mathrm{~s})$ and the distribution of surface load in the workpiece (in MPa)

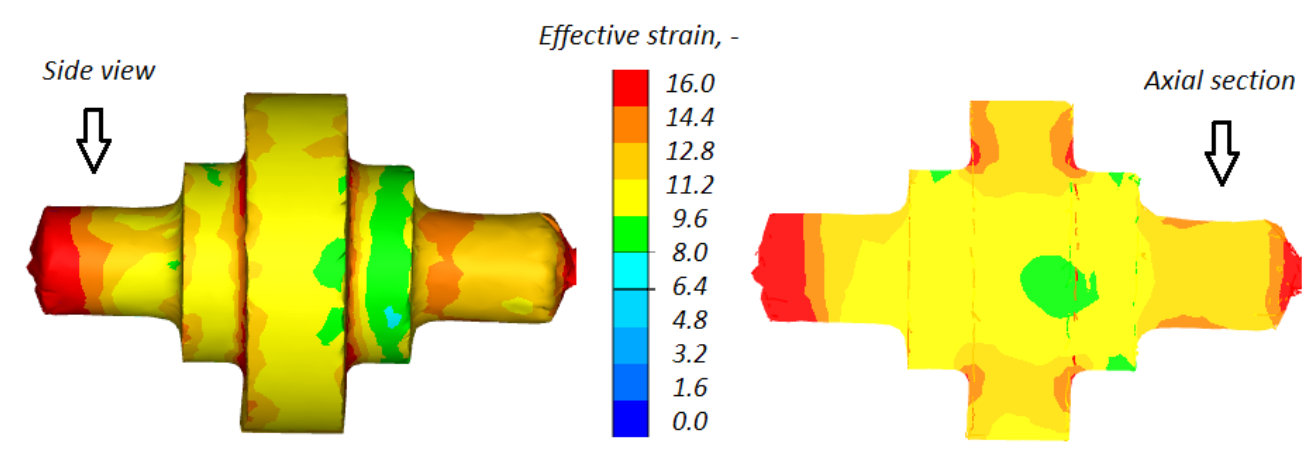

Damage function, -
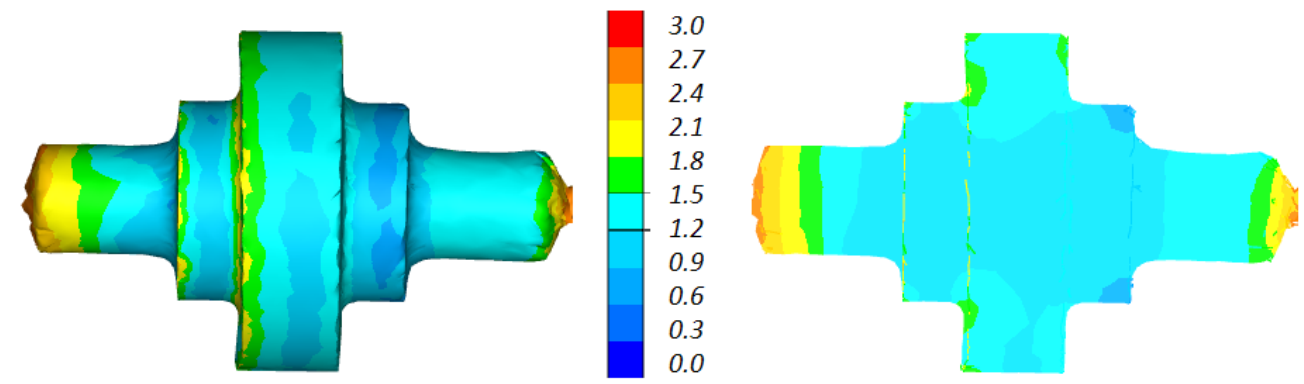

Temperature, ${ }^{\circ} \mathrm{C}$
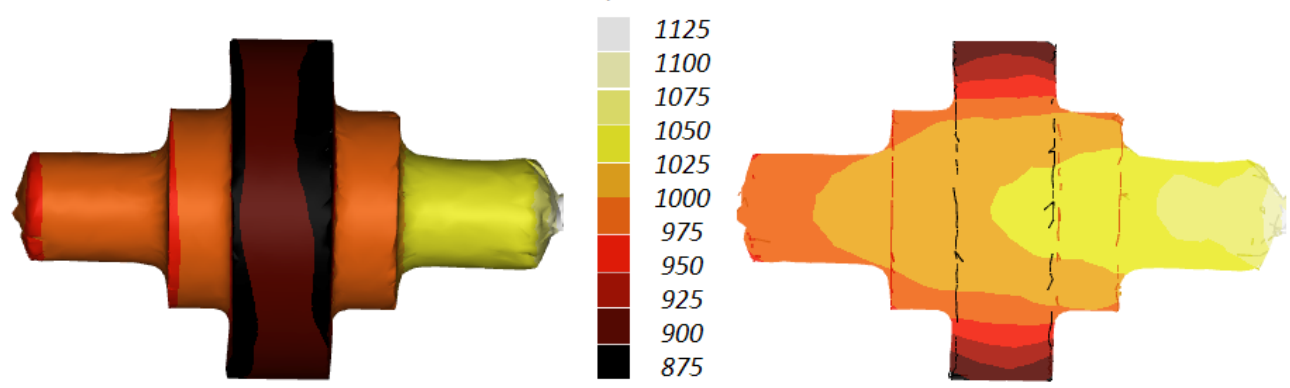

Fig. 14. FEM-simulated distributions of (starting from top): effective strains, damage function and temperature in a stepped shaft produced by HWR 
if one considers the fact that in an advanced stage of the process every revolution of the rolls produces three shafts at the same time (in different stages). Given the overall dimensions of the rolls, it can be presumed that their deformation during the rolling process will be insignificant and thus will have no great effect on forming accuracy.

Figure 16 shows the variations in torque in the HWR process for producing a stepped shaft. The variations are significant, which means that the production process should be run with the use of rolling mills provided with flywheels to store energy. The mean torque of the roll (in a late stage of the process, i.e. for $t>8 \mathrm{~s}$ ) is $10.3 \mathrm{kNm}$, which corresponds to an average power demand of 16.2 $\mathrm{kW}$ per each roll.

\section{BALL PIN}

The proposed HWR method can also be used to produce relatively long parts. One example of such parts is a ball pin with a length that is 2.8 times bigger than its maximum diameter (Fig. 17).

To form a ball pin with the above design, the authors used two-coil rolls shown in Fig. 18. The use of thereby designed tools significantly increases forming efficiency because they enable formation of two parts simultaneously during one revolution of the rolls. The spreading angle and the angle of inclination of the side wall of the wedge were set by intuition, based on the authors' considerable experience in designing standard CWR processes.

The numerical modeling of the HWR process for producing a ball pin rested upon the following assumptions: the workpiece is made of $\mathrm{C} 45$ steel preheated to the temperature of $1150^{\circ} \mathrm{C}$; the temperature of the rolls is maintained constant at $50^{\circ} \mathrm{C}$, while the temperature of other tools is set to $300^{\circ} \mathrm{C}$; the rolls are rotated at the speed of 15 revolutions per minute, and the feed angle is set to $7.5^{\circ}$ relative to the axis of the workpiece (i.e. a bar with a $29 \mathrm{~mm}$ diameter and a length of $225 \mathrm{~mm}$ ). Other parameters were set identically as in the cases discussed previously.

The proposed design of the HWR process for producing ball pins was verified using the finite element method. Fig. 19 shows the variations in shape of the part in an advanced (steady) stage of the forming process, after the first part has been produced. HWR is a low waste process. When formed, parts are cut off by the cutters located at

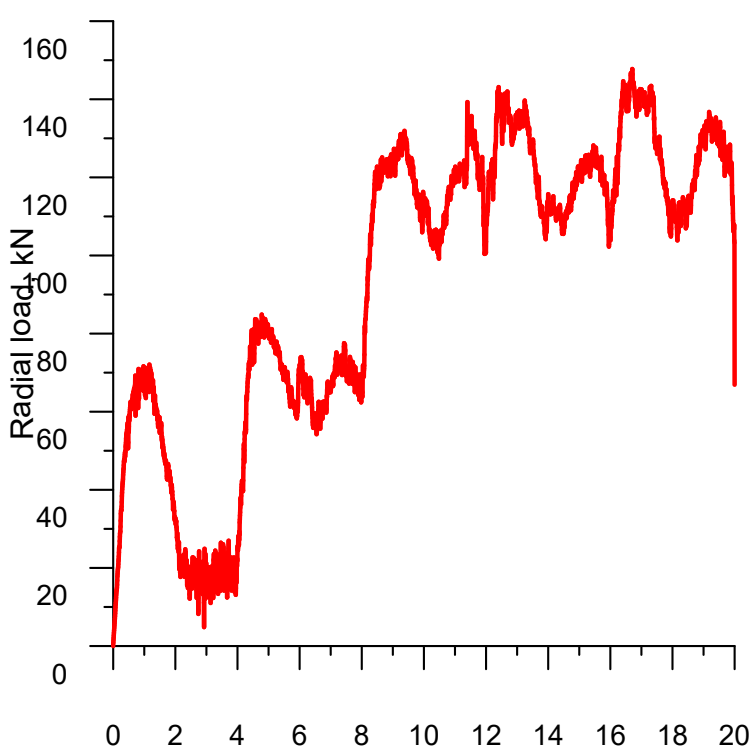

Fig. 15. Radial load in HWR for a stepped shaft

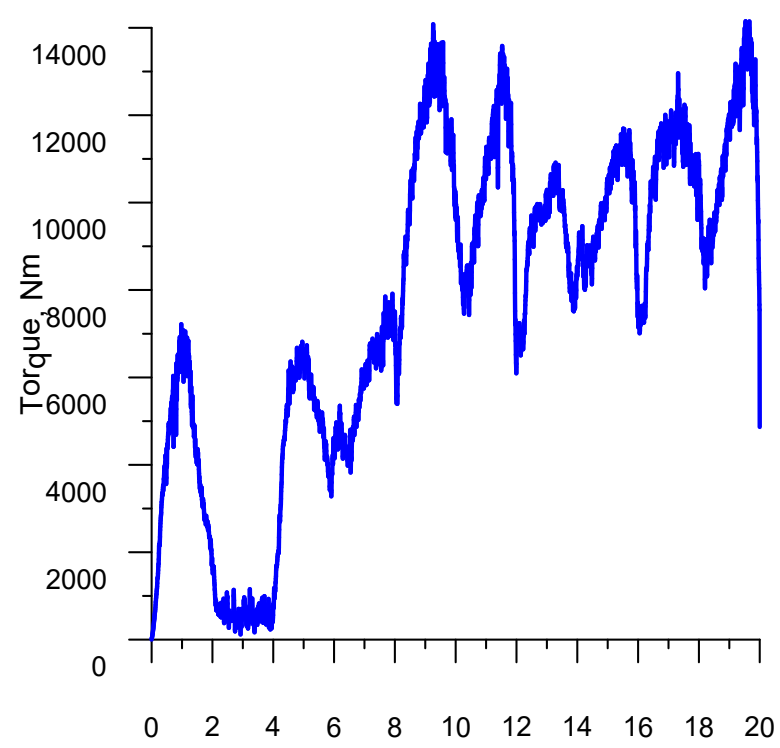

Fig. 16. Torque on the roll in HWR for a stepped shaft

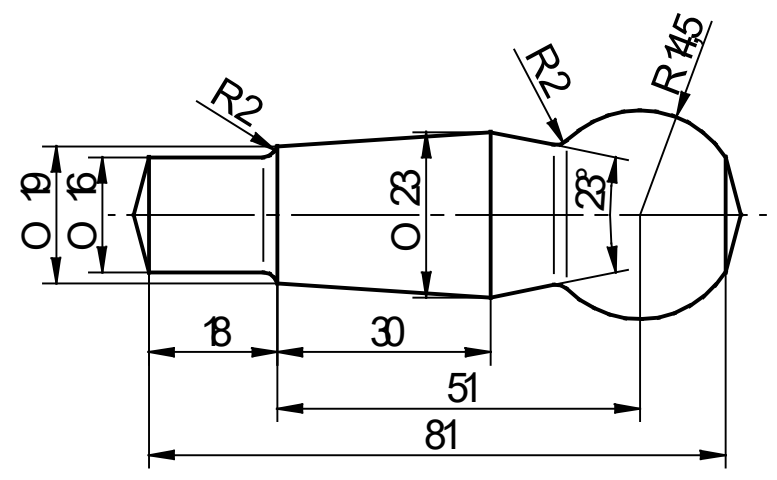

Fig. 17. Schematic design of a ball pin 

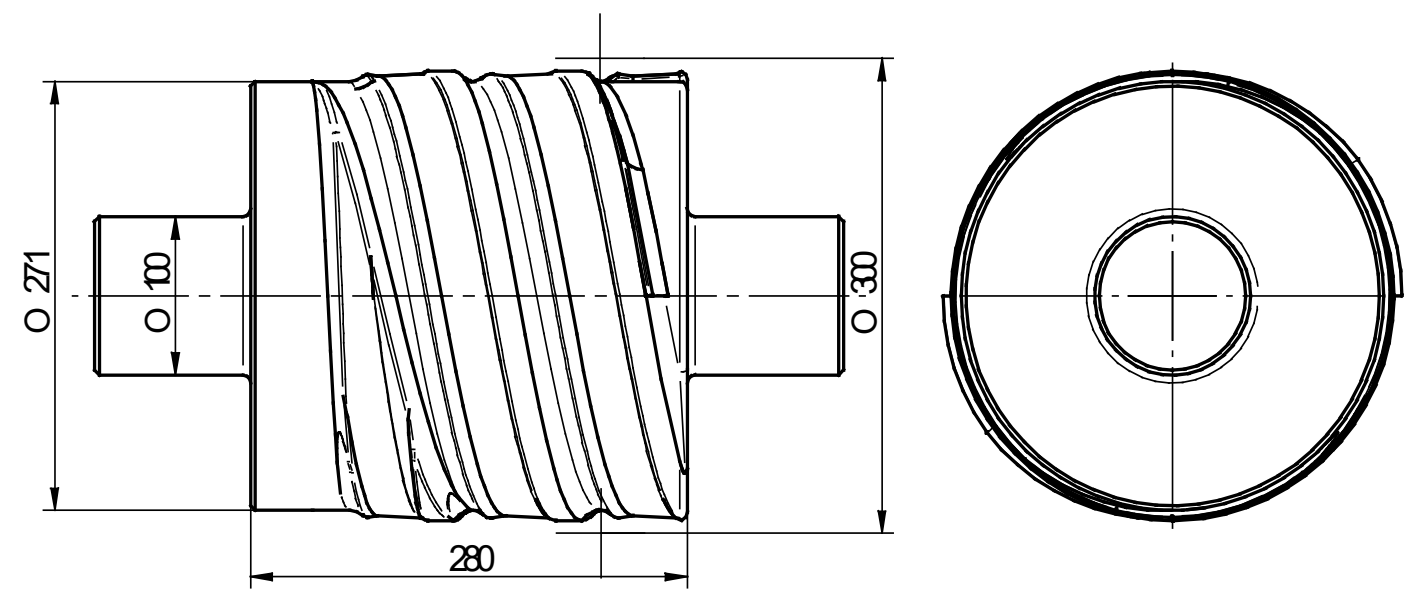

Fig. 18. Tool with a two-coil helical wedge used in HWR for a ball pin

the end zone of the tool. The numerical results clearly demonstrate that the HWR method can be used to produce ball pins.

In the investigated rolling process a single part is formed during 1.5 revolutions of the rolls, which is equal to 6 seconds. During this time, the workpiece comes into contact with colder tools to which heat is carried away. At the same time, due to exchange of the friction work into the work of deformation, a large amount of heat is released, partly compensating for the heat loss caused by the contact of the workpiece with the colder tools. As a result, the temperature of the workpiece decreases to $100 \div 150{ }^{\circ} \mathrm{C}$. Nevertheless, it remains in the hot forming temperature range throughout the entire forming process (Fig. 19).
Figure 20 shows the distribution of effective strains in the axial section and on the surface of the produced part. As can be seen in the figure, the strains are distributed in the same way as in the previously discussed cases. The pattern of their distribution is strongly connected with cross sectional reduction, while their values are the highest in the separation zone (impact of the cutters). Besides, the high values of effective strain point to rapid flow of the metal in a circumferential direction.

Figure 21 shows the distribution of the damage function determined in accordance with the Cockroft-Latham criterion. It can be observed that the damage function takes the highest values on the workpiece ends, i.e. in the area of impact

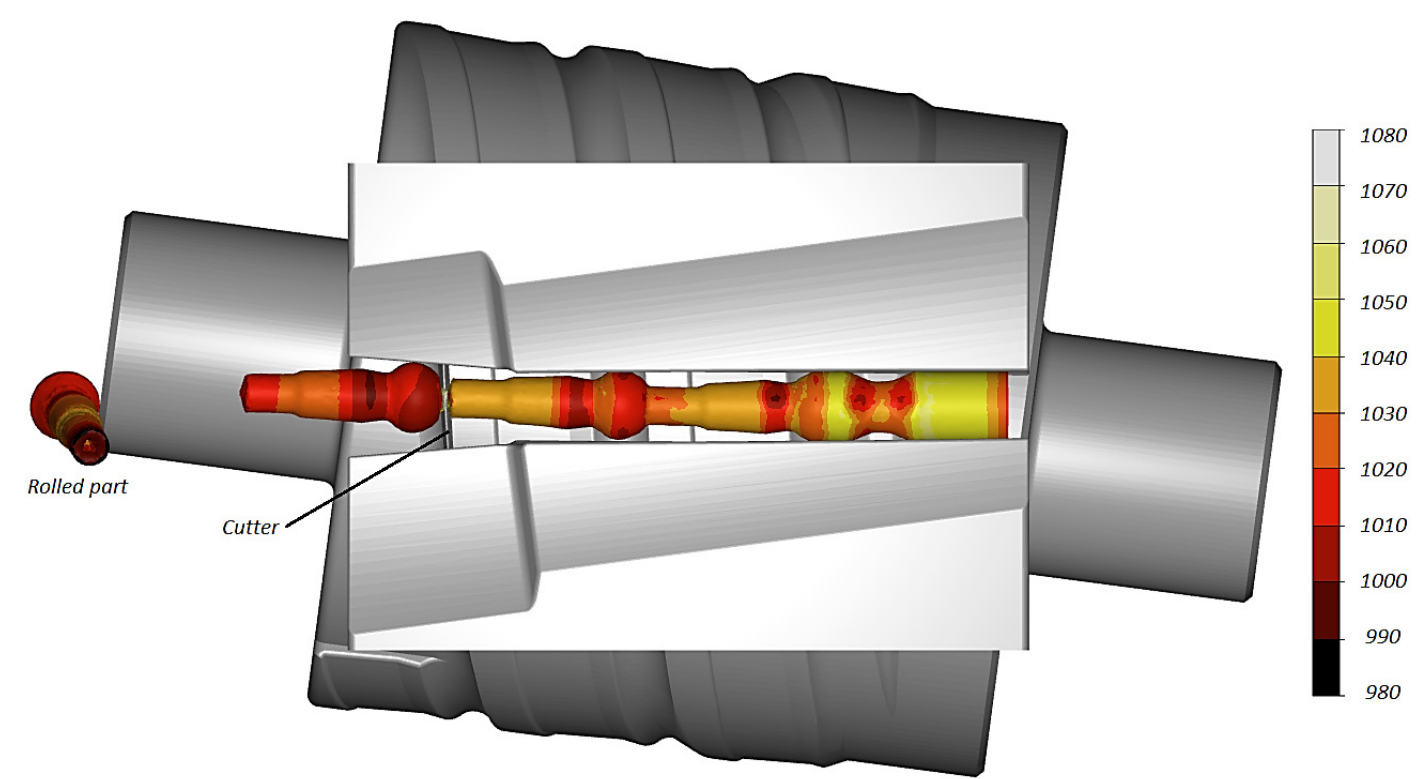

Fig. 19. Changes in workpiece shape in an advanced stage of HWR, i.e. after producing the first ball pin, and the distribution of temperature in the workpiece (in ${ }^{\circ} \mathrm{C}$ ) 


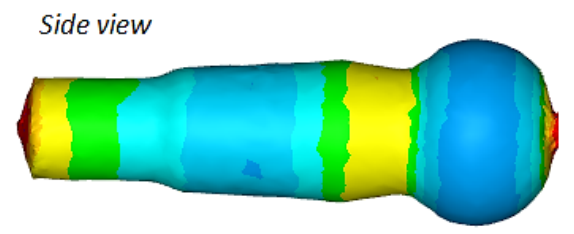

Axial section
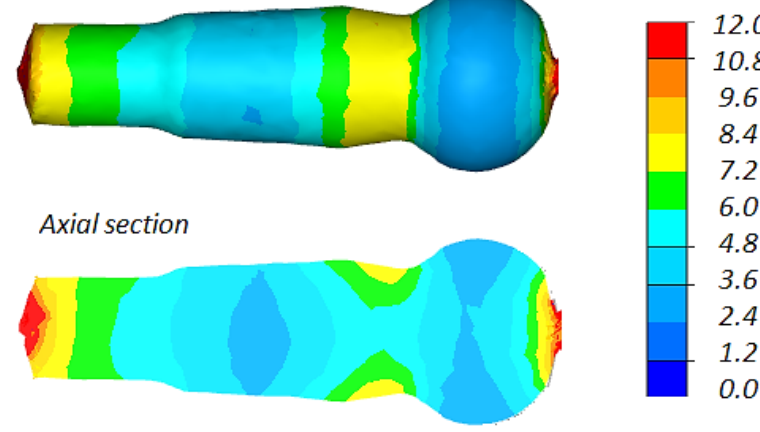

Fig. 20. Distribution of effective strains in a ball pin produced by HWR using two-coil helical wedges

of the cutters. It is also in this area that coherence of the material is disturbed, leading to desired separation of the formed ball pin from the rest of the material. On the other hand, cracking should not occur in the axial zone of the ball pin.

In addition, variations in force parameters in the rolling process were determined using FEM. They are illustrated in Fig. 22 (radial load) and Fig. 23 (torque acting on the roll). The behavior of these parameters is characterized by an oscillatory pattern (observed previously), which reflects a cyclic contact between the workpiece and the helical wedges.

\section{CONCLUSIONS}

The paper investigated the possibility of producing axisymmetric parts (rotary cutter bodies, stepped shafts, ball pins) by an innovative helicalwedge rolling process designed at the Lublin University of Technology. Based on the numerical results, the following conclusions can be made:

- the proposed HWR method can be used to produce axisymmetric parts with complex shapes;

- the distribution of effective strains in parts produced by HWR is typical of cross and helical rolling processes, where the strains increase due to rapid metal flow in a circumferential direction;

- the pattern of variations in the damage function indicates that there the workpiece axis should be free from crack occurrence;

- despite a long forming time in HWR, the temperature of the workpiece does not decrease beyond the hot forming temperature range;

- the load on the guides is many times lower than that acting on the rolls;

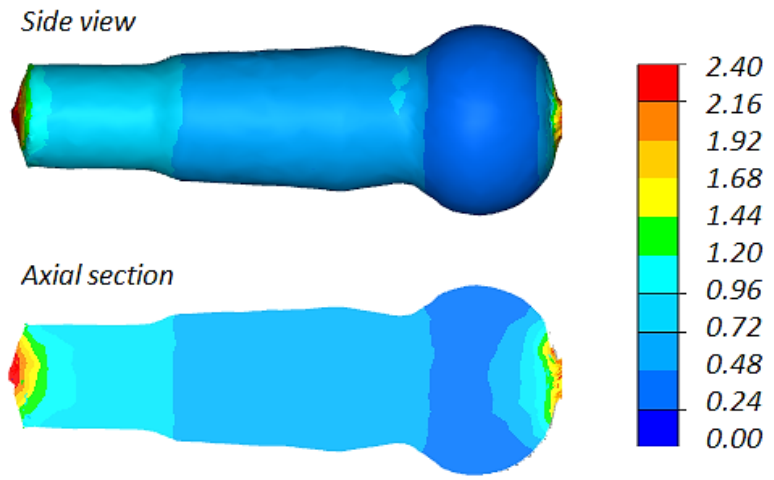

Fig. 21. Distribution of the damage function in a ball pin produced by HWR using two-coil helical wedges

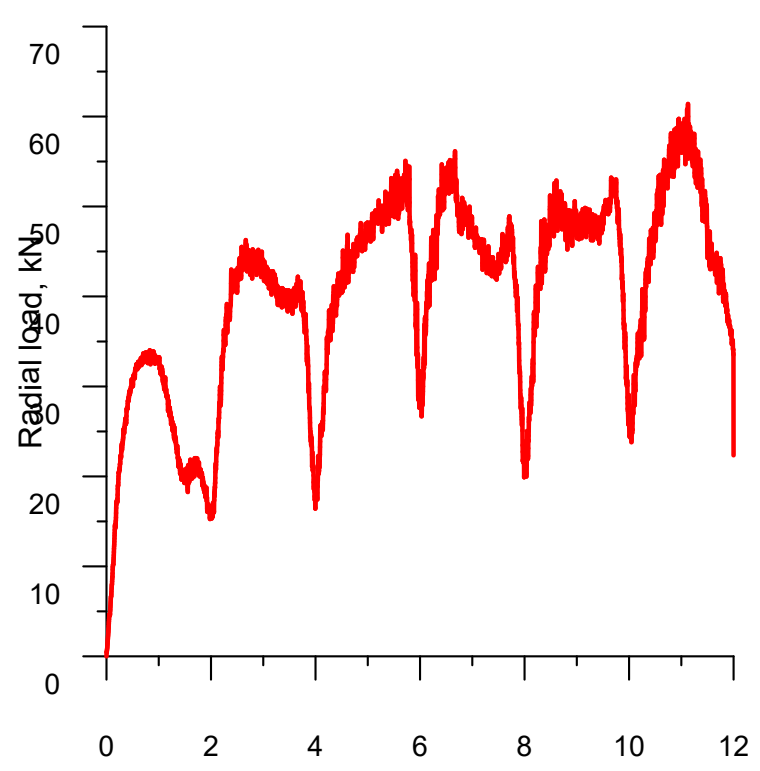

Fig. 22. Radial load on the roll in HWR by two-coil helical wedges

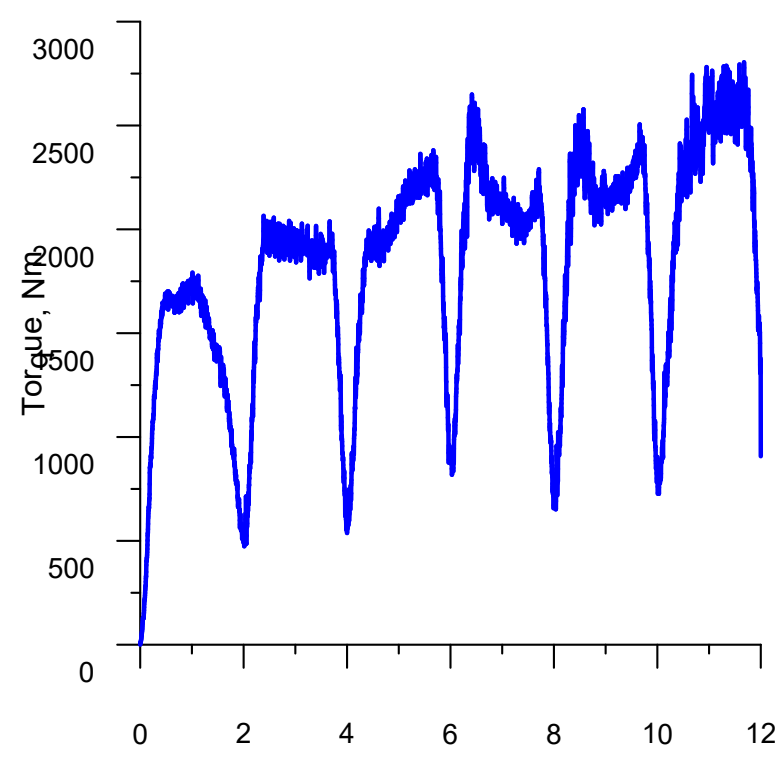

Fig. 23. Torque on the roll in HWR by two-coil helical wedges 
- the HWR process is characterized by oscillatory variations in the torque, which suggests using rolling mills provided with flywheels;

- the research on HWR should be continued to establish theoretical and technological fundamentals of this promising metal forming method.

\section{REFERENCES}

1. Lange K. Handbook of Metal Forming. Ed. McGraw-Hill Book Company 1985

2. Hodge G. O. Machine for forming balls. US Patent No. 1,665,361 (10.04.1928)

3. Klamp P. Mill for rolling articles of circular section and irregular profile. US Patent No. 2,060,087 (10.11.1936)

4. Šor E. R. New processes of rolling. Moskva: Wyd. Metallurgizdat 1960 (in Russian)

5. Awano T., Danno A. Continuous transverse rolling process and apparatus. US Patent No. 3,602,025 (31.08.1971)

6. Pater, Z. Cross-Wedge Rolling. In Comprehensive Materials Processing; Ed.; Elsevier Ltd., vol. 3 (2014), 211-279

7. Pater Z., Tomczak J. Helical rolling of balls for ball mills. Wyd. Politechniki Lubelskiej, Lublin 2012 (in Polish)

8. Pater Z., Tomczak J., Kazanecki J. Helical - wedge rolling of steel bails. Steel Research International 2012, Spec. Ed. Metal Forming 2010, 79-82

9. Pater Z., Tomczak J., Bartnicki J., Lovell M. R., Menezes P. L. Experimental and numerical analysis of helical-wedge rolling process for producing steel balls. International Journal of Machine Tools \& Manufacture, vol. 67 (2013), 1-7

10. Tomczak J., Pater Z., Bartnicki J. Skew rolling of balls in multiple helical impressions. Archives of Metallurgy and Materials, vol. 58 (2013) no 4, 1072-1076

11. Piedrahita F., Garcia Arana L., Chastel Y. Three Dimensional Numerical Simulation of Cross-Wedge Rolling of Bars, Proceedings of the $8^{\text {th }}$ International Conference on Technology of Plasticity ICTP, Verona, 2005 (CD ROM)

12. Meyer M., Stonis M., Behrnes B., A.: Cross wedge rolling preforms for crankshafts, Key Engineering Materials, vols. 504-506 (2012), 205-210

13. Meyer M., Stonis M., Behrens B.: Cross wedge rolling and bi-directional forging of preforms for crankshafts. Production Engineering. Research and Development, vol. 9 (2015), 61-71

14. Novella M. F., Ghiotti A., Bruschi S., Bariani P. F. Ductile damage modeling at elevated temperature applied to the cross wedge rolling of AA6082-T6 bars. Journal of Materials Processing Technology, vol. 222 (2015), 259-267

15. Kpodzo K., Fourment L., Lanse P., Montmitonnet P. An accurate time integration scheme for arbitrary rotation motion: application to metal forming simulation. International Journal of Material Forming, vol. 9 (2016), 71-84

16. Shu X. D., Wei J., Liu C. Study on the control of end quality by one closed cross wedge rolling based wedge block. Metalurgija, vol. 56 (2017) no 1, 123-126

17. Pater Z., Tomczak J., Bulzak T. Analysis of wedge rolling process of stepped shaft. Mechanik, vol. 86 (2013) no. 11, 966-970 (in Polish) 